\title{
Modeling and Analysis of Supply Chain Inventory Model with two-warehouses and Economic Load Dispatch Problem Using Genetic Algorithm
}

\author{
Ajay Singh Yadav \\ Assistant professor, Department of Mathematics \\ SRM University NCR Campus Modinagar, Ghaziabad, U.P., India. \\ ajay29011984@gmail.com
}

\begin{abstract}
In this paper a deterministic supply chain inventory model has been developed for deteriorating items having a ramp type demand with the effects of inflation with two-storage facilities and Economic Load Dispatch Problem Using Genetic Algorithm.. The owned warehouse (OW) has a fixed capacity of W units; the rented warehouse (RW) has unlimited capacity. Here, we assumed that the inventory holding cost in RW is higher than those in OW and Economic Load Dispatch Problem Using Genetic Algorithm. Shortages in inventory are allowed and partially backlogged and it is assumed that the inventory deteriorates over time at a variable deterioration rate and Economic Load Dispatch Problem Using Genetic Algorithm. The effect of inflation has also been considered for various costs associated with the supply chain inventory system. Numerical example is also used to study the behavior of the model and Economic Load Dispatch Problem Using Genetic Algorithm. Cost minimization technique is used to get the expressions for total cost and other parameters and Economic Load Dispatch Problem Using Genetic Algorithm.
\end{abstract}

Keywords:- Economic Load Dispatch Problem, Genetic Algorithm, Two-warehouses, Production rate, Inflation, supply chain.

\section{Introduction}

Many researchers extended the EOQ model to time-varying demand patterns. Some researchers discussed of inventory models with linear trend in demand. The main limitations in linear-time varying demand rate is that it implies a uniform change in the demand rate per unit time. This rarely happens in the case of any commodity in the market. In recent years, some models have been developed with a demand rate that changes exponentially with time. For seasonal products like clothes, Air conditions etc. at the end of their seasons the demand of these items is observed to be exponentially decreasing for some initial period. Afterwards, the demand for the products becomes steady rather than decreasing exponentially. It is believed that such type of demand is quite realistic. Such type situation can be represented by ramp type demand rate.

An important issue in the inventory theory is related to how to deal with the unfulfilled demands which occur during shortages or stock outs. In most of the developed models researchers assumed that the shortages are either completely backlogged or completely lost. The first case, known as backordered or backlogging case, represent a situation where the unfulfilled demand is completely back ordered. In the second case, also known as lost sale case, we assume that the unfulfilled demand is completely lost.

Furthermore, when the shortages occur, some customers are willing to wait for backorder and others would turn to buy from other sellers. In many cases customers are conditioned to a shipping delay and may be willing to wait for a short time in order to get their first choice. For instance, for fashionable commodities and high-tech products with short product life cycle, the willingness of a customer to wait for backlogging is diminishing with the length of the waiting time. Thus the length of the waiting time for the next replenishment would determine whether the backlogging would be accepted or not. In many real life situations, during a shortage period, the longer the waiting time is, the smaller is the backlogging rate would be. Therefore, for realistic business situations the backlogging rate should be variable and dependent on the waiting time for the next replenishment. Many researchers have modified inventory policies by considering the "time proportional partial backlogging rate".

Genetic algorithms are very different from most of the traditional optimization methods. Genetic algorithms need design space to be converted into genetic space. So, genetic algorithms work with a coding of variables. The advantage of working with a coding of variable space is that coding discreteness the search space even though the function may be continuous. A more striking difference between genetic algorithms and most of the traditional optimization methods is that GA uses a population of points at one time in contrast to the single 
point approach by traditional optimization methods. This means that GA processes a number of designs at the same time. As we have seen earlier to improve the search direction in traditional optimization methods transition rules are used and they are deterministic in nature but GA uses randomized operators. Random operators improve the search space in an adaptive manner.

\section{Related work}

Buzacott (1975) developed the first EOQ model taking inflationary effects into account. In this model, a uniform inflation was assumed for all the associated costs and an expression for the EOQ was derived by minimizing the average annual cost. Misra $(1975,1979)$ investigated inventory systems under the effects of inflation. Bierman and Thomas (1977) suggested the inventory decision policy under inflationary conditions. An economic order quantity inventory model for deteriorating items was developed by Bose et al. (1995). Authors developed inventory model with linear trend in demand allowing inventory shortages and backlogging. The effects of inflation and time-value of money were incorporated into the model. Hariga and Ben-Daya (1996) then discussed the inventory replenishment problem over a fixed planning horizon for items with linearly timevarying demand under inflationary conditions. Ray and Chaudhuri (1997) developed a finite time-horizon deterministic economic order quantity inventory model with shortages, where the demand rate at any instant depends on the on-hand inventory at that instant. The effects of inflation and time value of money were taken into account. The effects of inflation and time-value of money on an economic order quantity model have been discussed by Moon and Lee (2000). The two-warehouse inventory models for deteriorating items with constant demand rate under inflation were developed by Yang (2004). The shortages were allowed and fully backlogged in the models. Some numerical examples for illustration were provided. Models for ameliorating / deteriorating items with time-varying demand pattern over a finite planning horizon were proposed by Moon et al. (2005). The effects of inflation and time value of money were also taken into account. An inventory model for deteriorating items with stock-dependent consumption rate with shortages was produced by Hou (2006). Model was developed under the effects of inflation and time discounting over a finite planning horizon. Jaggi et al. (2007) presented the optimal inventory replenishment policy for deteriorating items under inflationary conditions using a discounted cash flow (DCF) approach over a finite time horizon. Shortages in inventory were allowed and completely backlogged and demand rate was assumed to be a function of inflation. Two stage inventory problems over finite time horizon under inflation and time value of money was discussed by Dey et al. (2008).

In this direction the concept of two warehouse modeling was introduced by Hartely (1976) which is later on carried by many other researchers. Hartely, in his research article does not consider the transportation cost incurred for transporting items from rented warehouse to own warehouse or retail shop/distribution center/retail outlet . The paper introduced by Hartely was extended by Srama (1987) introducing the transportation cost as one of the key factor affecting the inventory cost and infinite refilling rate. Further Murdeshwar and Sayhe (1985) extended the paper of Sarma with consideration of finite refilling rate. A research article was established by Dave (1988) introducing mentioning an additional case of bulk release pattern for each finite and infinite refilling rates of Murdeshwar paper and corrected the errors of this paper giving whole answer of the model given by Sarma. The concept of two ware house introduced by Hartely, further used by many researchers and still continuing with adding different business environment and cost affecting components of the inventory system. The above inventory model was analyzed by Bhunia and Maiti (1998) a sensitivity analysis is presented graphically on the optimal average cost. Zhou and Yang (2005) introduces a two-warehouse inventory model for items with stock-level dependent demand rate. Kar et. al (2001) developed a Deterministic inventory model with two levels of storage, a linear trend in demand and a fixed time horizon. Murdeshwar, Goswami and Chaudhuri (1992) developed an economic order quantity model for items with two levels of storage for a linear trend in demand. They derived the condition when to rent a warehouse and used a simple algorithm to find the maximum total profit per unit time. Ghosh and Chakrabarty (2009) introduced an order level inventory model under two level storage systems with time dependent demand.In all these models the cases of non-deteriorating items were established. Jiang et. al (2015) developed "Joint optimization of preventive maintenance and inventory policies for multi-unit systems subject to deteriorating spare part inventory" (The deterioration of the inventory affects decision-making and increases losses. Block replacement and periodic review inventory policies were here used to evaluate a joint optimization problem for multi-unit systems in the presence of inventory deterioration). Wagner et. al (1999) introducing "A genetic algorithm solution for one-dimensional bundled stock cutting" (The nature of this problem is such that the traditional approaches of linear programming with an integer round-up procedure or sequential heuristics are not effective. A good solution to this problem must consider trim loss, stock usage and ending inventory levels). Sadeghi et. al (2015) extended "Two parameter tuned multi-objective evolutionary algorithms for a bi-objective vendor managed inventory model with trapezoidal fuzzy demand" (A bi-objective vendor managed inventory (BOVMI) model for a supply chain problem with a single vendor and multiple retailers, in which the demand is fuzzy and the vendor manages the retailers' inventory in a central warehouse). Diabat et. al (2014) developed "Hybrid algorithm for a vendor managed inventory system in a two- 
echelon supply chain"(We try to find the optimal sales quantity by maximizing profit, given as a nonlinear and non-convex objective function. For such complicated combinatorial optimization problems, exact algorithms and optimization commercial software such as LINGO are inefficient, especially on practical-size problems). Guchhait et. al (2013) extended "Two storage inventory model of a deteriorating item with variable demand under partial credit period" (The supplier also offers a partial permissible delay in payment even if the order quantity is less than the fixed ordered label. For display of goods, retailer has one warehouse of finite capacity at the heart of the market place and another warehouse of infinite capacity (that means capacity of second warehouse is sufficiently large) situated outside the market but near to first warehouse. Units are continuously transferred from second warehouse to first and sold from first warehouse. Combining the features of Particle Swarm Optimization (PSO) and Genetic Algorithm (GA) a hybrid heuristic (named Particle Swarm-Genetic Algorithm (PSGA)) is developed and used to find solution of the proposed model). Bera et. al (2012) introducing "Inventory model with fuzzy lead-time and dynamic demand over finite time horizon using a multiobjective genetic algorithm" (A realistic inventory problem with an infinite rate of replenishment over a prescribed finite but imprecise time horizon is formulated considering time dependent ramp type demand, which increases with time. Lead time is also assumed as fuzzy in nature. Shortages are allowed and backlogged partially. Two models are considered depending upon the ordering policies of the decision maker). Wang et. al (2011) developed "Location and allocation decisions in a two-echelon supply chain with stochastic demand - A genetic-algorithm based solution" (Decisions include locating a number of factories among a finite set of potential sites and allocating task assignment between factories and marketplaces to maximize profit). Kannan et. al (2010) extended "A genetic algorithm approach for solving a closed loop supply chain model: A case of battery recycling" (In order to overcome this issue, it is necessary to setup a logistics network for arising goods flow from end users to manufacturers. In this study, the optimum usage of secondary lead recovered from the spent lead-acid batteries for producing new battery is presented). Yun et. al (2009) extended "Hybrid genetic algorithm with adaptive local search scheme for solving multistage-based supply chain problems" (The optimal design of supply chain (SC) is a difficult task, if it is composed of the complicated multistage structures with component plants, assembly plants, distribution centres, retail stores and so on. It is mainly because that the multistage-based SC with complicated routes may not be solved using conventional optimization methods). Farahani et. al (2008) introducing "A genetic algorithm to optimize the total cost and service level for just-intime distribution in a supply chain" (A bi-objective model is set up for the distribution network of a threeechelon supply chain, with two objective functions: minimizing costs, and minimizing the sum of backorders and surpluses of products in all periods). Nachiappan et. al (2007) extended "A genetic algorithm for optimal operating parameters of VMI system in a two-echelon supply chain" (The operational parameters to the above model are: sales quantity and sales price that determine the channel profit of the supply chain, and contract price between the vendor and the buyer, which depends upon the understanding between the partners on their revenue sharing). Altiparmak et. al (2006) developed "A genetic algorithm approach for multi-objective optimization of supply chain networks" (Supply chain network (SCN) design is to provide an optimal platform for efficient and effective supply chain management. It is an important and strategic operations management problem in supply chain management, and usually involves multiple and conflicting objectives such as cost, service level, resource utilization, etc). Maiti et. al (2006) introducing "An application of real-coded genetic algorithm (RCGA) for mixed integer non-linear programming in two-storage multi-item inventory model with discount policy" (This GA is based on Roulette wheel selection, whole arithmetic crossover and non-uniform mutation. Here, mutation is carried out for the fine-tuning capabilities of the system by non-uniform operator whose action depends on the age of the population. This methodology has been applied in solving multiple price break structure and implemented for multi-item deterministic inventory control system having two separate storage facilities (owned and rented warehouse) due to limited capacity of the existing storage (owned warehouse). Also, demand rate is a linear function of selling price, time and non-linearly on the frequency of advertisement. The model is formulated with infinite replenishment and shortages are not allowed. The stocks of rented warehouse (RW) are transported to the owned warehouse (OW) in bulk-release rule). Chan et. al (2003) introducing "Solving the multi-buyer joint replenishment problem with a modified genetic algorithm" (The joint replenishment problem (JRP) is a multi-item inventory problem. The objective is to develop inventory policies that minimize the total costs (comprised of holding cost and setup cost) over the planning horizon). Mondal et. al (2003) extended "Multi-item fuzzy EOQ models using genetic algorithm" (It uses genetic algorithms (GAs) with mutation and whole arithmetic crossover. Here, mutation is carried out along the weighted gradient direction using the random step lengths based on Erlang and Chi-square distributions. These methodologies have been applied to solve multi-item fuzzy EOQ models under fuzzy objective goal of cost minimization and imprecise constraints on warehouse space and number of production runs with crisp/imprecise inventory costs). Xie, et. al (2002) extended "Heuristic genetic algorithms for general capacitated lot-sizing problems" (The lot-sizing problems address the issue of determining the production lot-sizes of various items appearing in consecutive production stages over a given finite planning horizon. In general capacitated lot-sizing problems, the product structure can be a general acyclic network, the capacity constraints can be very sophisticated, and all the known parameters 
can be time-varying). Disney et. al (2000) developed "Genetic algorithmoptimisation of a class of inventory control systems" (Benchmark performance characteristics. Five are considered herein and include inventory recovery to "shock" demands; in-built filtering capability; robustness to production lead-time variations; robustness to pipeline level information fidelity; and systems selectivity. A genetic algorithm for optimising system performance, via these five vectors is described). Padhy and Simon (2015) soft computing with matlab programming.

\section{Assumptions and Notations}

In developing the mathematical model of the inventory system the following assumptions are being made:

1. A single item is considered over a prescribed period $T$ units of time.

2. The demand rate $\mathrm{D}(\mathrm{t})$ at time $\mathrm{t}$ is deterministic and taken as a ramp type function of time i.e. $\mathrm{D}(\mathrm{t})=\mathrm{Ae}^{-\lambda\{\mathrm{t}-(\mathrm{t}-\mu) \mathrm{H}(\mathrm{t}-\mu)\}}, \mathrm{A}>0, \lambda>0$ where $\mathrm{H}(\mathrm{t}-\mu)$ is the Heaviside's function defined as $H(t-\mu)=\left\{\begin{array}{l}0, t<\mu \\ 1, t \geq \mu\end{array}\right.$

3. The replenishment rate is infinite and lead-time is zero.

4. When the demand for goods is more than the supply. Shortages will occur. Customers encountering shortages will either wait for the vender to reorder (backlogging cost involved) or go to other vendors (lost sales cost involved). In this model shortages are allowed and the backlogging rate is $\exp (-\delta \mathrm{t})$, when inventory is in shortage. The backlogging parameter $\delta$ is a positive constant.

5. The variable rate of deterioration in both warehouse is taken as $\theta(\mathrm{t})=\theta \mathrm{t}$. Where $0<\theta<<1$ and only applied to on hand inventory.

6. No replacement or repair of deteriorated items is made during a given cycle.

7. The owned warehouse (OW) has a fixed capacity of W units; the rented warehouse (RW) has unlimited capacity.

8. The goods of OW are consumed only after consuming the goods kept in RW.

In addition, the following notations are used throughout this paper:

The inventory level in OW at any time t.

The inventory level in RW at any time t.

$\mathrm{W}$

The capacity of the own warehouse.

Q The ordering quantity per cycle.

$\mathrm{T} \quad$ Planning horizon.

$\mathrm{r} \quad$ Inflation rate.

$\mathrm{C}_{1} \quad$ The holding cost per unit per unit time in OW.

$\mathrm{C}_{2} \quad$ The holding cost per unit per unit time in RW. where $\mathrm{C}_{1}<\mathrm{C}_{2}$

$\mathrm{C}_{\mathrm{d}} \quad$ The deterioration cost per unit.

$\mathrm{C}_{3} \quad$ The shortage cost per unit per unit time.

$\mathrm{C}_{4} \quad$ The opportunity cost due to lost sales.

$\mathrm{C}^{\prime} \quad$ The replenishment cost per order.

$P_{R} \quad$ Production rate which is taken as demand dependent i.e. $P_{R}=\prod D(t)$

$R_{R} \quad$ Retailer rate which is taken as demand dependent i.e. $R_{R}=\varepsilon D(t)$

$D_{R} \quad$ Distribution rate which is taken as demand dependent i.e. $D_{R}=\delta D(t)$

$\mathrm{TC}_{1} \quad$ Transportation Cost of Manufacturer to between warehouses

$\mathrm{TC}_{2} \quad$ Transportation Cost of warehouses to between Distribution centers

\section{(i) Production Model}

\section{Formulation and Solution of the Model}

$\mathrm{P}_{\mathrm{R}}=$ Production Rate - Demand

$$
\begin{aligned}
& =\prod \mathrm{D}(\mathrm{t})-\mathrm{D}(\mathrm{t}) \\
& =\prod\left(A e^{-\lambda\{t-(t-\mu) H(t-\mu)\}}\right)-\left(A e^{-\lambda\{t-(t-\mu) H(t-\mu)\}}\right)
\end{aligned}
$$


(ii) Two-warehouses inventory Model

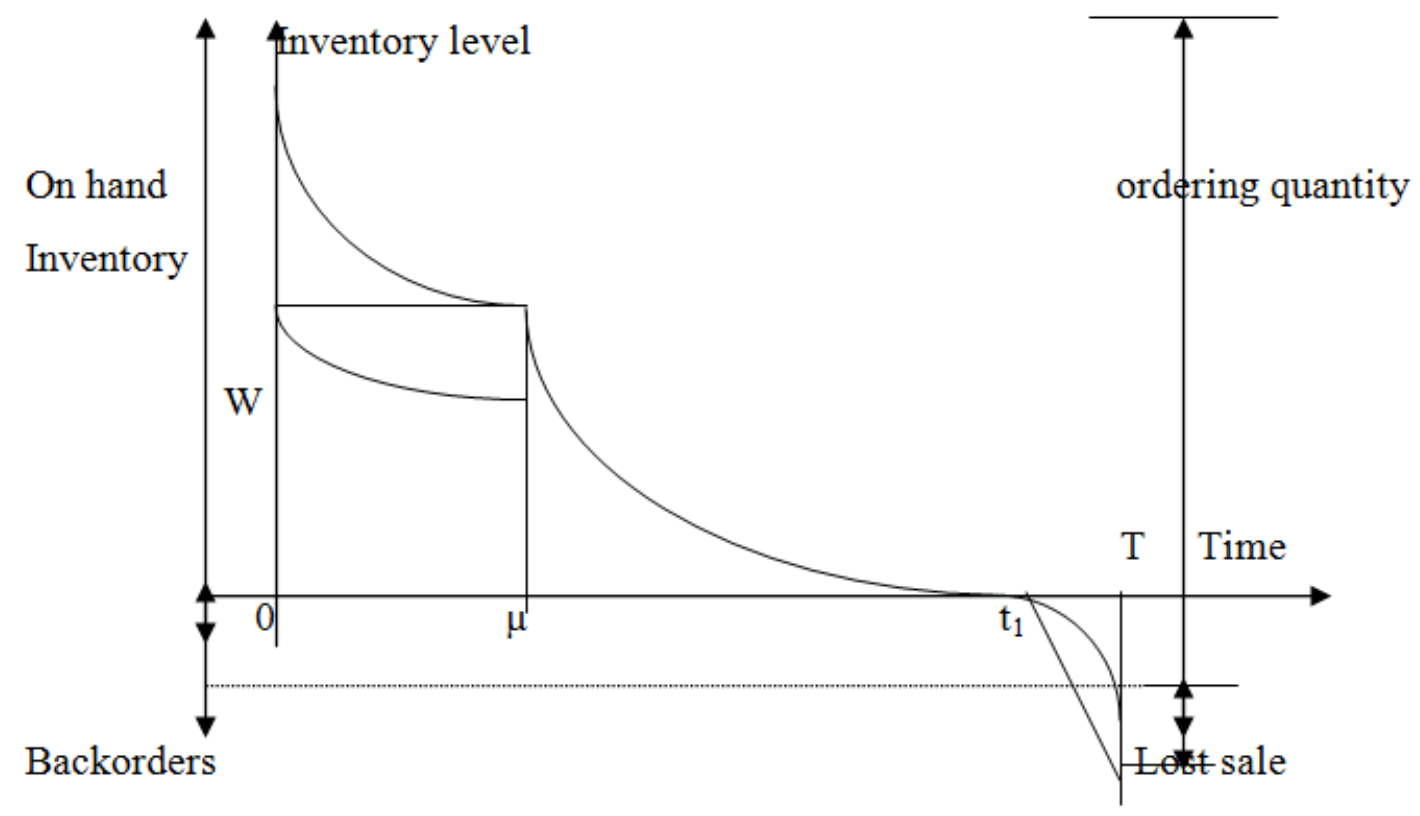

Fig.1: Graphical representation of a two-warehouse inventory system.

The inventory levels at $\mathrm{OW}$ are governed by the following differential equations:

$$
\begin{array}{ll}
\frac{d I_{o}(t)}{d t}=-\theta(t) I(t), & 0 \leq \mathrm{t}<\mu \\
\frac{d I_{o}(t)}{d t}+\theta(t) I(t)=-A e^{-\lambda \mu}, & \mu \leq \mathrm{t} \leq \mathrm{t}_{1}
\end{array}
$$

And

$$
\frac{d I_{o}(t)}{d t}=-A e^{-\lambda \mu} e^{-\delta t},
$$$$
\mathrm{t}_{1} \leq \mathrm{t} \leq \mathrm{T}
$$

with the boundary conditions,

$\mathrm{I}_{0}(0)=\mathrm{W}$ and $\mathrm{I}\left(\mathrm{t}_{1}\right)=0$

The solutions of equations (1), (2) and (3) are given by

$$
\begin{array}{ll}
I_{o}(t)=W e^{-\theta t^{2} / 2}, & 0 \leq \mathrm{t}<\mu \\
I_{o}(t)=A e^{-\lambda \mu}\left\{\left(t_{1}-t\right)+\theta \frac{\left(t_{1}^{3}-t^{3}\right)}{6}\right\} e^{-\theta t^{2} / 2}, & \mu \leq \mathrm{t} \leq \mathrm{t}_{1}
\end{array}
$$

And $I_{o}(t)=\frac{A}{\delta} e^{-\lambda \mu}\left\{e^{-\delta t}-e^{-\delta t_{1}}\right\}, \quad \mathrm{t}_{1} \leq \mathrm{t} \leq \mathrm{T}$

The inventory level at RW is governed by the following differential equations:

$$
\frac{d I_{r}(t)}{d t}+\theta(t) I(t)=-A e^{-\lambda t}, \quad 0 \leq \mathrm{t}<\mu
$$

With the boundary condition $\mathrm{I}_{\mathrm{r}}(0)=0$, the solution of the equation (8) is

$$
I_{r}(t)=A\left\{(\mu-t)-\frac{\lambda}{2}\left(\mu^{2}-t^{2}\right)+\frac{\theta}{6}\left(t_{1}^{3}-t^{3}\right)\right\} e^{-\theta t^{2} / 2}, \quad \mu \leq \mathrm{t} \leq \mathrm{t}_{1}
$$


Due to continuity of $\mathrm{I}_{\mathrm{o}}(\mathrm{t})$ at point $\mathrm{t}=\mu$, it follows from equations (5) and (6), one has

$$
\begin{aligned}
& W e^{-\theta \mu^{2} / 2}=A e^{-\lambda \mu}\left\{\left(t_{1}-\mu\right)+\theta \frac{\left(t_{1}^{3}-\mu^{3}\right)}{6}\right\} e^{-\theta \mu^{2} / 2} \\
& W=A e^{-\lambda \mu}\left\{\left(t_{1}-\mu\right)+\theta \frac{\left(t_{1}^{3}-\mu^{3}\right)}{6}\right\}
\end{aligned}
$$

The total average cost consists of following elements:

(i) Ordering cost per cycle $=\mathrm{C}^{\prime}$

(ii) Holding cost per cycle $\left(\mathrm{C}_{\mathrm{HO}}\right)$ in $\mathrm{OW}$

$$
\begin{aligned}
C_{H O}= & C_{1}\left[\int_{0}^{\mu} I_{0}(t) e^{-r t} d t+\int_{\mu}^{t_{1}} I_{0}(t) e^{-r(\mu+t)} d t\right] \\
C_{H O}= & C_{1}\left\{W\left(\mu-\frac{r \mu^{2}}{2}-\frac{\theta \mu^{3}}{6}\right)+A e^{-\lambda(\mu+r)}\left[\frac{t_{1}^{2}}{2}-\frac{r t_{1}^{3}}{6}+\frac{\theta t_{1}^{4}}{12}-\frac{r \theta}{20} t_{1}^{5}\right.\right. \\
& -\frac{\mu}{2}\left(2 t_{1}-\mu\right)-\frac{\theta \mu}{24}\left(4 t_{1}^{3}-\mu^{3}\right)+\frac{r \mu^{2}}{6}\left(3 t_{1}-2 \mu\right)+\frac{r \theta \mu^{2}}{30} \\
& \left.\left.\left(5 t_{1}^{3}-3 \mu^{3}\right)+\frac{\theta \mu^{3}}{24}\left(4 t_{1}-3 \mu\right)\right]\right\}
\end{aligned}
$$

(iii) Holding cost per cycle $\left(\mathrm{C}_{\mathrm{HR}}\right)$ in $\mathrm{RW}$

$$
\begin{aligned}
& C_{H R}=C_{2}\left[\int_{0}^{\mu} I_{r}(t) e^{-r t} d t\right] \\
& C_{H R}=C_{2} A\left[\frac{\mu^{2}}{2}-\frac{(3 \lambda+r)}{6} \mu^{3}+\left(\frac{\theta}{12}+\frac{\lambda r}{8}\right) \mu^{4}-\left(\frac{r \theta}{20}-\frac{\lambda \theta}{30}\right) \mu^{5}\right]
\end{aligned}
$$

(iv) Cost of deteriorated units per cycle $\left(C_{D}\right)$

$$
\begin{aligned}
= & C_{d}\left[\int_{0}^{\mu} \theta t I_{r}(t) e^{-r t} d t+\int_{0}^{\mu} \theta t I_{0}(t) e^{-r t} d t+\int_{\mu}^{t_{1}} \theta t I_{0}(t) e^{-r(t+\mu)} d t\right] \\
= & C_{d} \theta\left\{\left[A\left(\frac{1}{6} \mu^{3}-\left(\frac{\lambda}{4}+\frac{r}{12}\right) \mu^{4}+\left(\frac{\theta}{40}+\frac{r \lambda}{15}\right) \mu^{5}-\left(\frac{r \theta}{36}-\frac{\lambda \theta}{24}\right) \mu^{6}\right)\right]\right. \\
& +W\left(\frac{\mu^{2}}{2}-\frac{r \mu^{3}}{3} \frac{\theta \mu^{4}}{8}\right)+A e^{-\mu(\lambda+r)}\left(\frac{t_{1}^{3}}{6}-\frac{r t_{1}^{4}}{12}+\frac{\theta t_{1}^{5}}{40}-\frac{r \theta t_{1}^{6}}{36}-\frac{\mu^{2}}{6}\right. \\
& \left(3 t_{1}-2 \mu\right)-\frac{\theta \mu^{2}}{60}\left(5 t_{1}^{3}-2 \mu^{3}\right)-\frac{r \mu^{3}}{12}\left(4 t_{1}-3 \mu\right)-\frac{r \theta \mu^{3}}{36}\left(2 t_{1}^{3}-\mu^{3}\right) \\
& \left.\left.-\frac{\theta \mu^{4}}{40}\left(5 t_{1}-4 \mu\right)\right)\right\}
\end{aligned}
$$


(v) Shortage cost per cycle $\left(\mathrm{C}_{\mathrm{S}}\right)$

$$
\begin{aligned}
& =C_{3}\left[\int_{t_{1}}^{T}-I_{0}(t) e^{-r\left(t_{1}+t\right)} d t\right] \\
& =\frac{-\mathrm{AC}_{3} \mathrm{e}^{-\left(\mathrm{rt}_{1}+\lambda \mu\right)}}{\delta}\left[\int_{\mathrm{t}_{1}}^{\mathrm{T}} \mathrm{e}^{-(\mathrm{r}+\delta) \mathrm{t}} \mathrm{dt}-\mathrm{e}^{-\delta \mathrm{t}_{1}} \int_{\mathrm{t}_{1}}^{\mathrm{T}} \mathrm{e}^{-\mathrm{rt}} \mathrm{dt}\right] \\
& =\frac{\mathrm{AC}_{3} \mathrm{e}^{-\left(\mathrm{rt}_{1}+\lambda \mu\right)}}{\delta \mathrm{r}(\delta+\mathrm{r})}\left[\delta \mathrm{e}^{-(\delta+\mathrm{r}) \mathrm{t}_{1}}+\mathrm{e}^{-\mathrm{rT}}\left\{\mathrm{re}^{-\delta \mathrm{T}}-(\delta+\mathrm{r}) \mathrm{e}^{-\delta \mathrm{t}_{1}}\right\}\right]
\end{aligned}
$$

(vi) Opportunity cost due to lost sales per cycle $\left(\mathrm{C}_{0}\right)$

$$
\begin{aligned}
& =\mathrm{C}_{4} \int_{\mathrm{t}_{1}}^{\mathrm{T}} \mathrm{A}\left(1-\mathrm{e}^{-\delta \mathrm{t}}\right) \mathrm{e}^{-\lambda \mu} \mathrm{e}^{-\mathrm{r}\left(\mathrm{t}_{1}+\mathrm{t}\right)} \mathrm{dt} \\
& =\frac{\mathrm{C}_{4} \mathrm{~A} \mathrm{e}^{-\left(\lambda \mu+\mathrm{rt}_{1}\right)}}{\mathrm{r}(\delta+\mathrm{r})}\left[\mathrm{e}^{-r \mathrm{r}_{1}}\left\{(\delta+\mathrm{r})-\mathrm{re}^{-\delta \mathrm{t}_{1}}\right\}-\mathrm{e}^{-\mathrm{rT}}\left\{(\delta+\mathrm{r})-\mathrm{re}^{-\delta \mathrm{T}}\right\}\right]
\end{aligned}
$$

Therefore, the total average cost per unit time of our model is obtained as follows $\mathrm{K}\left(\mathrm{t}_{1}, \mathrm{~T}\right)=\frac{1}{\mathrm{~T}}[$ Ordering cost + Holding cost in $\mathrm{OW}+$ Holding cost in $\mathrm{RW}+$

Shortage cost + Opportunity cost ]

$$
\begin{aligned}
& K\left(t_{1}, T\right)=\left[\frac { 1 } { T } \left\{C^{\prime}+C_{1}\left\{W\left(\mu-\frac{r \mu^{2}}{2}-\frac{\theta \mu^{3}}{6}\right)+A e^{-\lambda(\mu+r)}\left[\frac{t_{1}^{2}}{2}-\frac{r t_{1}^{3}}{6}+\frac{\theta t_{1}^{4}}{12}-\frac{r \theta}{20} t_{1}^{5}\right.\right.\right.\right. \\
& -\frac{\mu}{2}\left(2 t_{1}-\mu\right)-\frac{\theta \mu}{24}\left(4 t_{1}^{3}-\mu^{3}\right)+\frac{r \mu^{2}}{6}\left(3 t_{1}-2 \mu\right)+\frac{r \theta \mu^{2}}{30}\left(5 t_{1}^{3}-3 \mu^{3}\right)+ \\
& \left.\left.\frac{\theta \mu^{3}}{24}\left(4 t_{1}-3 \mu\right)\right]\right\}+C_{2} A\left[\frac{\mu^{2}}{2}-\frac{(3 \lambda+r)}{6} \mu^{3}+\left(\frac{\theta}{12}+\frac{\lambda r}{8}\right) \mu^{4}-\left(\frac{r \theta}{20}-\frac{\lambda \theta}{30}\right) \mu^{5}\right] \\
& +C_{d} \theta\left\{\left[A\left(\frac{1}{6} \mu^{3}-\left(\frac{\lambda}{4}+\frac{r}{12}\right) \mu^{4}+\left(\frac{\theta}{40}+\frac{r \lambda}{15}\right) \mu^{5}-\left(\frac{r \theta}{36}-\frac{\lambda \theta}{24}\right) \mu^{6}\right)\right]\right. \\
& +W\left(\frac{\mu^{2}}{2}-\frac{r \mu^{3}}{3} \frac{\theta \mu^{4}}{8}\right)+A e^{-\mu(\lambda+r)}\left(\frac{t_{1}^{3}}{6}-\frac{r t_{1}^{4}}{12}+\frac{\theta t_{1}^{5}}{40}-\frac{r \theta t_{1}^{6}}{36}-\frac{\mu^{2}}{6}\right. \\
& \left(3 t_{1}-2 \mu\right)-\frac{\theta \mu^{2}}{60}\left(5 t_{1}^{3}-2 \mu^{3}\right)-\frac{r \mu^{3}}{12}\left(4 t_{1}-3 \mu\right)-\frac{r \theta \mu^{3}}{36}\left(2 t_{1}^{3}-\mu^{3}\right) \\
& \left.\left.-\frac{\theta \mu^{4}}{40}\left(5 t_{1}-4 \mu\right)\right)\right\}+\frac{A C_{3} e^{-\left(r t_{1}+\lambda \mu\right)}}{\delta r(\delta+r)}\left[\delta e^{-(\delta+r) t_{1}}+e^{-r T}\left\{r e^{-\delta T}-(\delta+r) e^{-\delta t_{1}}\right\}\right] \\
& \left.\left.+\frac{C_{4} A e^{-\left(\lambda \mu+r t_{1}\right)}}{r(\delta+r)}\left[e^{-r t_{1}}\left\{(\delta+r)-r e^{-\delta t_{1}}\right\}-e^{-r T}\left\{(\delta+r)-r e^{-\delta T}\right\}\right]\right\}\right]
\end{aligned}
$$


(iii) Transportation Cost (Manufacturer to between warehouses)

$\mathrm{TC}_{1}=\mathrm{T}_{1} \mathrm{D}(\mathrm{t})$

$$
=\mathrm{T}_{1}\left(A e^{-\lambda\{t-(t-\mu) H(t-\mu)\}}\right)
$$

(iv) Transportation Cost (warehouses to between Distribution centers)

$\mathrm{TC}_{2}=\mathrm{T}_{2} \mathrm{D}(\mathrm{t})$

$$
=\mathrm{T}_{2}\left(A e^{-\lambda\{t-(t-\mu) H(t-\mu)\}}\right)
$$

(v)

\section{Distribution centre}

$\mathrm{D}_{\mathrm{R}}=\delta \mathrm{D}(\mathrm{t})$

$$
=\delta\left(A e^{-\lambda\{t-(t-\mu) H(t-\mu)\}}\right)
$$

(vi) Retailer Cost

$$
\begin{aligned}
\mathrm{R}_{\mathrm{R}} & =\varepsilon \mathrm{D}(\mathrm{t}) \\
& =\varepsilon\left(A e^{-\lambda\{t-(t-\mu) H(t-\mu)\}}\right)
\end{aligned}
$$

Total Supply Chain inventory cost $=$ Production Rate + Transportation Cost + Two-warehouses inventory + Transportation Cost + Distribution Rate + Retailer Rate

$$
\begin{aligned}
& \text { TSCIC }=\mathrm{P}_{\mathrm{R}}+\mathrm{TC}_{1}+K\left(t_{1}, T\right)+\mathrm{TC}_{2}+\mathrm{D}_{\mathrm{R}}+\mathrm{R}_{\mathrm{R}} \\
& \text { TSCIC }=\left[\prod\left(A e^{-\lambda\{t-(t-\mu) H(t-\mu)\}}\right)-\left(A e^{-\lambda\{t-(t-\mu) H(t-\mu)\}}\right)\right]+\mathrm{T}_{1}\left(A e^{-\lambda\{t-(t-\mu) H(t-\mu)\}}\right)+ \\
& {\left[\frac { 1 } { T } \left\{C^{\prime}+C_{1}\left\{W\left(\mu-\frac{r \mu^{2}}{2}-\frac{\theta \mu^{3}}{6}\right)+A e^{-\lambda(\mu+r)}\left[\frac{t_{1}^{2}}{2}-\frac{r t_{1}^{3}}{6}+\frac{\theta t_{1}^{4}}{12}-\frac{r \theta}{20} t_{1}^{5}\right.\right.\right.\right.} \\
& -\frac{\mu}{2}\left(2 t_{1}-\mu\right)-\frac{\theta \mu}{24}\left(4 t_{1}^{3}-\mu^{3}\right)+\frac{r \mu^{2}}{6}\left(3 t_{1}-2 \mu\right)+\frac{r \theta \mu^{2}}{30}\left(5 t_{1}^{3}-3 \mu^{3}\right)+ \\
& \left.\left.\frac{\theta \mu^{3}}{24}\left(4 t_{1}-3 \mu\right)\right]\right\}+C_{2} A\left[\frac{\mu^{2}}{2}-\frac{(3 \lambda+r)}{6} \mu^{3}+\left(\frac{\theta}{12}+\frac{\lambda r}{8}\right) \mu^{4}-\left(\frac{r \theta}{20}-\frac{\lambda \theta}{30}\right) \mu^{5}\right] \\
& +C_{d} \theta\left\{\left[A\left(\frac{1}{6} \mu^{3}-\left(\frac{\lambda}{4}+\frac{r}{12}\right) \mu^{4}+\left(\frac{\theta}{40}+\frac{r \lambda}{15}\right) \mu^{5}-\left(\frac{r \theta}{36}-\frac{\lambda \theta}{24}\right) \mu^{6}\right)\right]\right. \\
& +W\left(\frac{\mu^{2}}{2}-\frac{r \mu^{3}}{3} \frac{\theta \mu^{4}}{8}\right)+A e^{-\mu(\lambda+r)}\left(\frac{t_{1}^{3}}{6}-\frac{r t_{1}^{4}}{12}+\frac{\theta t_{1}^{5}}{40}-\frac{r \theta t_{1}^{6}}{36}-\frac{\mu^{2}}{6}\right. \\
& \left(3 t_{1}-2 \mu\right)-\frac{\theta \mu^{2}}{60}\left(5 t_{1}^{3}-2 \mu^{3}\right)-\frac{r \mu^{3}}{12}\left(4 t_{1}-3 \mu\right)-\frac{r \theta \mu^{3}}{36}\left(2 t_{1}^{3}-\mu^{3}\right) \\
& \left.\left.-\frac{\theta \mu^{4}}{40}\left(5 t_{1}-4 \mu\right)\right)\right\}+\frac{A C_{3} e^{-\left(r t_{1}+\lambda \mu\right)}}{\delta r(\delta+r)}\left[\delta e^{-(\delta+r) t_{1}}+e^{-r T}\left\{r e^{-\delta T}-(\delta+r) e^{-\delta t_{1}}\right\}\right] \\
& \left.\left.+\frac{C_{4} A e^{-\left(\lambda \mu+r t_{1}\right)}}{r(\delta+r)}\left[e^{-r t_{1}}\left\{(\delta+r)-r e^{-\delta t_{1}}\right\}-e^{-r T}\left\{(\delta+r)-r e^{-\delta T}\right\}\right]\right\}\right] \\
& +\mathrm{T}_{2}\left(A e^{-\lambda\{t-(t-\mu) H(t-\mu)\}}\right)+\delta\left(A e^{-\lambda\{t-(t-\mu) H(t-\mu)\}}\right)+\varepsilon\left(A e^{-\lambda\{t-(t-\mu) H(t-\mu)\}}\right)
\end{aligned}
$$




\section{Proposed And Economic Load Dispatch Problem Using Genetic Algorithm}

The objective is to find the optimal solution so that the minimum fuel cost is obtained subject to certain equality and inequality constraints. The problem may be expressed as a function which consists of the cost function and the constraints.

In this work equality constraint reflects real power balance and the inequality constraint reflects the limit of real power generation.

\section{Mathematically the formulation may be given as follows}

Minimize

$\Phi=\sum_{i=1}^{N} \Phi_{i} \Psi_{i}$

Where $\Phi_{i} \Psi_{i}$ is the fuel cost function of generating unit I and $P_{i}$ is the generation output of unit I in MW Subject to:

a. Power balance constraints is given as follows

$$
\sum_{i=1}^{N} \Psi_{i}-\Psi_{D}=0
$$

Where $\Psi_{D}$ is the total real power demand in MW

b. Generating capacity constraints is given as follows

$\Psi_{i}^{\min } \leq \Psi_{i} \leq \Psi_{i}^{\max }$ for $\mathrm{i}=1,2, \ldots \ldots \ldots \ldots . \mathrm{N}$

Where $\Psi_{i}^{\min }$ and $\Psi_{i}^{\max }$ are the minimum and maximum output generation of unit i.

The fuel cost function considering valve-point effect of the generating unit is given as follows $\Phi^{*}\left(\Psi_{i}\right)=\Phi_{i}\left(\Psi_{i}\right)+\left|e_{i} \sin \left(f_{i}\left[\Psi_{i}^{\min }-\Psi_{i}\right]\right)\right|$

Where

$\Phi_{i}\left(\Psi_{i}\right)=a_{i} \Psi_{i}^{2}+b_{i} \Psi_{i}+c_{i}$

Where $a_{i}, b_{i}, c_{i}$ are the fuel cot coefficients of unit $\mathrm{i}$, and $e_{i}$ and $f_{i}$ are the fuel cost coefficients of unit I with valve-point effect.

\section{Step-by-step procedure of GA applied to ELD Problem}

1. Generate the initial population of generating powers randomly.

2. Compute the total production cost of the generating power subject to the constraints in equation

a. Power balance constraints is given as follows

$$
\sum_{i=1}^{N} \Psi_{i}-\Psi_{D}=0
$$

Where $\Psi_{D}$ is the total real power demand in MW

b. Generating capacity constraints is given as follows

$$
\Psi_{i}^{\min } \leq \Psi_{i} \leq \Psi_{i}^{\max } \text { for } \mathrm{i}=1,2, \ldots \ldots \ldots \ldots . \mathrm{N}
$$

3. Compute the error $\Delta \Psi$ in satisfying the power balance constraint.

4. The objective is to minimize the cost and the $\Delta \Psi$. Thus the fitness function is developed based on these two parameters.

Fitness $=Z[(1-\%$ cost $)]+R[(1-\%$ Error $)]$

Where $Z, R(>0)$ : weighting coefficients

Error $=\sum_{i=1}^{N} \Psi_{i}-\Psi_{D}$

$\% \operatorname{Cost}=\frac{\text { String } \cos t-\text { Mincost }}{\text { Maxcost }- \text { Mincost }}$

$\%$ Error $=\frac{\text { String Error }- \text { MinError }}{\text { Max Error }- \text { MinError }}$

String cost $=$ String's cost of generation

Min cost $=$ the minimum objective function value within the population.

Max cost $=$ the maximum objective function value within the population. 
String error $=$ String's error in meeting the power balance constraint.

Min error $=$ the minimum constraint error within the population.

Max error $=$ the maximum constraint error within the population.

The total production cost and the error has to be minimized which leads to the maximization of fitness function

\section{Numerical Illustration}

To illustrate the model numerically the following parameter values are considered.
$\mathrm{A}=100$ units, $\mathrm{C}^{\prime}=$ Rs. 200 per order,
$\mathrm{r}=0.10$ unit,
$\mathrm{C}_{1}=$ Rs. 6.0 per unit per year,
$\lambda=0.2$ unit, $C_{2}=$ Rs. 20.0 per unit,
$\theta=0.004$ unit,
$\mathrm{C}_{3}=$ Rs. 24.0 per unit per year,
$\mu=0.4$ year, $\mathrm{C}_{4}=$ Rs. 8.0 per unit, $\delta=0.2$ unit,
$\mathrm{T}=1$ year,

Then for the minimization of total average cost and with help of software. the optimal policy can be obtained such as:

$\mathrm{t}_{1}=0.14892$ year, $\mathrm{S}=76.597235$ units and $\mathrm{K}=$ Rs.316.25354 per year.

Production Cost $=$ Rs. 78.256 per year $\quad$ Transportation Cost $=$ Rs. 28.246 per year

Distribution Cost $=$ Rs. 48.256 per year $\quad$ Retailer Cost= Rs. 98.256 per year

Total Supply Chain inventory cost= Rs.779.115354 per year

The aim of this section is to understand the application of both Binary GA and Continuous GA for economic dispatching of generating power in a power system satisfying the power balance constraint for system demand and total generating power as well as the generating power constraints for all units. Therefore a simple three generating unit test system is considered and the details of the test system are given in table

GA: real coded, population $=30$,

generations $=300$,

crossover probability $=0.5$,

mutation probability $=0.1$.

ELD:Units data for Five generators,

Total demand $=960$

Fuel Cost Coefficients for 5 generators system

\begin{tabular}{|l|l|l|l|l|l|}
\hline Unit & \multicolumn{1}{|c|}{$a_{i}$} & $b_{i}$ & \multicolumn{1}{|c|}{$c_{i}$} & \multicolumn{1}{|c|}{$\Psi_{i}^{\min }$} & \multicolumn{1}{|c|}{$\Psi_{i}^{\max }$} \\
\hline 1 & 261 & 8.25 & 0.00526 & 500 & 200 \\
\hline 2 & 78 & 8.21 & 0.00235 & 300 & 110 \\
\hline 3 & 25 & 8.45 & 0.00123 & 650 & 100 \\
\hline 4 & 42 & 8.23 & 0.00456 & 200 & 120 \\
\hline 5 & 564 & 8.20 & 0.00145 & 500 & 150 \\
\hline
\end{tabular}

Optimal Result of GA 5

\begin{tabular}{|c|l|}
\hline$\Psi_{1}(\mathrm{MW})$ & 456.25 \\
\hline$\Psi_{2}(\mathrm{MW})$ & 452.12 \\
\hline$\Psi_{3}(\mathrm{MW})$ & 156.32 \\
\hline$\Psi_{4}(\mathrm{MW})$ & 352.13 \\
\hline$\Psi_{5}(\mathrm{MW})$ & 325.58 \\
\hline Total Power $(\mathrm{MW})$ & 960 \\
\hline Total Cost $(\mathrm{Rs} / \mathrm{MWh})$ & 6547.21 \\
\hline
\end{tabular}




\section{Conclusion}

This study incorporates some realistic features that are likely to be associated with the inventory of any material. Decay (deterioration) overtime for any material product and occurrence of shortages in inventory are natural phenomenon in real situations and Economic Load Dispatch Problem Using Genetic Algorithm. supply chain inventory shortages are allowed in the model. In many cases customers are conditioned to a shipping delay, and may be willing to wait for a short time in order to get their first choice. Generally speaking, the length of the waiting time for the next replenishment is the main factor for deciding whether the backlogging will be accepted or not. The willingness of a customer to wait for backlogging during a shortage period declines with the length of the waiting time and Economic Load Dispatch Problem Using Genetic Algorithm. Thus, supply chain inventory shortages are allowed and partially backordered in the present chapter and the backlogging rate is considered as a decreasing function of the waiting time for the next replenishment. Demand rate is taken as exponential ramp type function of time, in which demand decreases exponentially for the some initial period and becomes steady later on. Since most decision makers think that the inflation does not have significant influence on the supply chain inventory policy, the effects of inflation are not considered in some inventory models and Economic Load Dispatch Problem Using Genetic Algorithm. However, from a financial point of view, an inventory represents a capital investment and must complete with other assets for a firm's limited capital funds. Thus, it is necessary to consider the effects of inflation on the supply chain inventory system. Therefore, this concept is also taken in this model. From the numerical illustration of the model, it is observed that the period in which inventory holds increases with the increment in backlogging and ramp parameters while inventory period decreases with the increment in deterioration and inflation parameters. Initial inventory level decreases with the increment in deterioration, inflation and ramp parameters while inventory level increases with the increment in backlogging parameter. The total average cost of the system goes on increasing with the increment in the backlogging and deterioration parameters while it decreases with the increment in inflation and ramp parameters and Economic Load Dispatch Problem Using Genetic Algorithm.. The proposed model can be further extended in several ways. For example, we could extend this deterministic model in to stochastic model. Also, we could extend the model to incorporate some more realistic features, such as quantity discount or the unit purchase cost, the inventory holding cost and others can also taken fluctuating with time and Economic Load Dispatch Problem Using Genetic Algorithm.

\section{Acknowledgement}

We would like to thank N.P. Padhy, and S.P Simon, books (Soft Computing with Matlab programming). Published in Oxford University Press 2015. We are very thankful to them for providing us the related data and make our research successful.

\section{References}

[1] Altiparmak, F., Gen, M., Lin, L., and Paksoy, T. (2006) "A genetic algorithm approach for multi-objective optimization of supply chain networks", Computers and Industrial Engineering, 51, 1, 196-215.

[2] B. J. Wagner (1999) "A genetic algorithm solution for one-dimensional bundled stock cutting", European Journal of Operational Research, 117, (2-1), 368-381.

[3] Bera, U.K., Maiti, M.K., and Maiti, M. (2012) "Inventory model with fuzzy lead-time and dynamic demand over finite time horizon using a multi-objective genetic algorithm", Computers and Mathematics with Applications, 64, 6, 1822-1838.

[4] Bhunia A.K. and Maiti M. (1998) "A two warehouse inventory model for deteriorating items with a linear trend in demand and shortages", Journal of the Operational Research Society, 49(3), 287-292.

[5] Chan, C.K., Cheung, B.K.S., and Langevin, A. (2003) "Multi-buyer joint replenishment problem with a modified genetic algorithm", Transportation Research Part B: Methodological, 37, 3, 291-299.

[6] Dave U. (1988) "On the EOQ models with two levels of storage", Opsearch, 25(3), 190-196.

[7] Diabat, A. (2014) "Hybrid algorithm for a vendor managed inventory system in a two-echelon supply chain", European Journal of Operational Research, 238, (1,1), 114-121.

[8] Disney, S.M., Naim, M.M., and Towill, D.R. (2000) "Genetic algorithm optimization of a class of inventory control systems", International Journal of Production Economics, 68, 3, 20, 259-278.

[9] Farahani, R.Z., and Elahipana, M. (2008) "A genetic algorithm to optimize the total cost and service level for just-in-time distribution in a supply chain", International Journal of Production Economics, 111, 2, 229-243.

[10] Ghosh, S. and Chakrabarty, T. (2009) "An order level inventory model under two level storage system with time dependent demand", Opsearch 46(3):335-344.

[11] Goswami A. and Chaudhuri, K.S. (1992) "An Economic order quantity model for items with two levels of storage for a linear trend in demand", Journal of Operational Research Society, 43, 157-167.

[12] Guchhait, P., Maiti, M.K., and Maiti, M. (2013) "Two storage inventory model of a deteriorating item with variable demand under partial credit period", Applied Soft Computing, Volume 13, 1, 428-448.

[13] Hartley, and Ronald, V. (1976) "On the EOQ model two levels of storage", Opsearch, 13, 190-196.

[14] Jiang, Y., Chen, M. and Zhou, D. (2015) "Joint optimization of preventive maintenance and inventory policies for multi-unit systems subject to deteriorating spare part inventory", Journal of Manufacturing Systems, 35, 191-205.

[15] Kannan, G., Sasikumar, P. and Devika, K. (2010) "A genetic algorithm approach for solving a closed loop supply chain model: A case of battery recycling", Applied Mathematical Modelling, 34, 3, 655-670.

[16] Kar, S., Bhunia, A.K. and Maiti, M. (2001) "Deterministic inventory model with two levels of storage, a linear trend in demand and a fixed time horizon", Computers and Operations Research, 28, 1315-1331. 
[17] Maiti, A.K., Bhunia, and Maiti, M. (2006) "An application of real-coded genetic algorithm (RCGA) for mixed integer non-linear programming in two-storage multi-item inventory model with discount policy", Applied Mathematics and Computation, 183, 2, 15, 903-915.

[18] Mondal, S., and Maiti, M. (2003) "Multi-item fuzzy EOQ models using genetic algorithm”, Computers and Industrial Engineering, 44, $1,105-117$.

[19] Murdeshwar, T.M., and Sathe, Y.S. (1985) "some aspects of lot size model with two levels of storage", Opsearch, 22(4), 255-262.

[20] Nachiappan, S.P., and Jawahar, N. (2007) "A genetic algorithm for optimal operating parameters of VMI system in a two-echelon supply chain", European Journal of Operational Research, 182, 3, 1, 1433-1452.

[21] Padhy, N.P., and Simon, S.P. (2015) soft computing with matlab programming, (book) oxford university press.

[22] Sadeghi, J., and Niaki, S.T.A. (2015) "Two parameter tuned multi-objective evolutionary algorithms for a bi-objective vendor managed inventory model with trapezoidal fuzzy demand", Applied Soft Computing, 30, 567-576.

[23] Sarma, K.V.S. (1987) "A deterministic order-level inventory model for deteriorating items with two storage facilities", European Journal Operations Research 29:70-72.

[24] Wang, K.J., Makond, B., and Liu, S.Y. (2011) "Location and allocation decisions in a two-echelon supply chain with stochastic demand - A genetic-algorithm based solution", Expert Systems with Applications, 38, 5, 6125-6131.

[25] Xie, J., and Dong, J. (2002) "Heuristic genetic algorithms for general capacitated lot-sizing problems", Computers and Mathematics with Applications, 44, 1-2, 263-276.

[26] Yun, Y.S., Moon, C., and Kim, D. (2009) "Hybrid genetic algorithm with adaptive local search scheme for solving multistage-based supply chain problems", Computers and Industrial Engineering, 56, 3, 821-838.

[27] Zhou, Y.W., Yang, S.L. (2005) "A two-warehouse inventory model for items with stock-level dependent demand rate", International Journal of Production Economics. 95, 215-228 .

[28] Bierman, H.J. and Thomas, J. (1977) Inventory decisions under inflationary conditions. Decision Sciences, 8(1), 151-155.

[29] Bose, S., Goswami, A., Chaudhuri, K.S. (1995) An EOQ model for deteriorating items with linear time dependent demand rate and shortage under inflation and time discounting. Journal of the Operational Research Society, 46, 777-782.

[30] Buzacott, J.A. (1975) Economic order quantities with inflation. Operational Research Quarterly, 26, 553-558.

[31] Dey, J.K., Mondal, S.K. and Maiti, M. (2008) Two storage inventory problem with dynamic demand and interval valued lead-time over finite time horizon under inflation and time-value of money. European Journal of Operational Research, 185, 170-194.

[32] Hariga, M.A. and Ben-Daya, M. (1996) optimal time-varying lot sizing models under inflationary conditions. European Journal of Operational Research, 89 (2), 313-325.

[33] Hou, K.L. (2006): An inventory model for deteriorating items with stock dependent consumption rate and shortages under inflation and time discounting. European Journal of Operational Research, 168, 463-474.

[34] Jaggi, C.K., Aggarwal, K.K. and Goel, S.K. (2007) Optimal order policy for deteriorating items with inflation induced demand. International Journal of Production Economics, 103 (2), 707-714.

[35] Misra, R.B. (1975) A study of inflationary effects on inventory systems. Logistic Spectrum, 9(3), 260-268.

[36] Misra, R.B. (1979) A note on optimal inventory management under inflation. Naval Research Logistics, 26, 161-165.

[37] Moon, I. And Lee, S. (2000): The effects of inflation and time-value of money on an economic order quantity model with a random product life cycle. European Journal of Operational Research, 125, 588-601.

[38] Moon, I., Giri, B.C. and Ko, B. (2005) Economic order quantity models for ameliorating / deteriorating items under inflation and time discounting. European Journal of Operational Research,162 (3), 773-785.

[39] Ray, J. and Chaudhuri, K.S. (1997) An EOQ model with stock-dependent demand, shortage, inflation and time discounting. International Journal of Production Economics, 53 (2), 171-180.

[40] Yang, H.L. (2004) Two-warehouse inventory models for deteriorating items with shortages under inflation. European Journal of Operational Research, 157, 344-356. 